\title{
Numerical Study of the Effect of Piston Shapes and Fuel Injection Strategies on In-Cylinder Conditions in a PFI/GDI Gasoline Engine
}

\author{
Xinyan Wang and Hua Zhao \\ Tianjin Univ., Brunel Univ. \\ Hui Xie and Bang-Quan He \\ Tianjin Univ.
}

\begin{abstract}
SI-CAI hybrid combustion, also known as spark-assisted compression ignition (SACI), is a promising concept to extend the operating range of $\mathrm{CAI}$ (Controlled Auto-Ignition) and achieve the smooth transition between spark ignition (SI) and CAI in the gasoline engine. In order to stabilize the hybrid combustion process, the port fuel injection ( $\mathrm{PFI})$ combined with gasoline direct injection (GDI) strategy is proposed in this study to form the in-cylinder fuel stratification to enhance the early flame propagation process and control the auto-ignition combustion process. The effect of bowl piston shapes and fuel injection strategies on the fuel stratification characteristics is investigated in detail using three-dimensional computational fluid dynamics (3-D CFD) simulations. Three bowl piston shapes with different bowl diameters and depths were designed and analyzed as well as the original flat piston in a single cylinder PFI/GDI gasoline engine. An engine operating load of IMEP=3.6 bar was selected to evaluate the effect of piston shapes on the in-cylinder conditions, including flow conditions, fuel stratification patterns, thermal conditions and fuel evaporation ratios. The GDI ratios and direct injection timings were also varied to find the most appropriate injection strategy to achieve optimal in-cylinder condition. The simulation results presented in this study clarified the effect of bowl piston shapes, GDI ratios and direct injection timings on the in-cylinder fuel stratification in a PFI/GDI gasoline engine. They would provide the fundamental knowledge and effective guidance on selecting the optimal bowl piston shape and fuel injection strategy to stabilize the SI-CAI hybrid combustion in the future experimental investigations.
\end{abstract}

CITATION: Wang, X., Zhao, H., Xie, H., and He, B., "Numerical Study of the Effect of Piston Shapes and Fuel Injection Strategies on In-Cylinder Conditions in a PFI/GDI Gasoline Engine," SAE Int. J. Engines 7(4):2014, doi:10.4271/2014-01-2670.

\section{INTRODUCTION}

Controlled Auto-ignition (CAI) combustion has been shown to effectively reduce the NOx emissions and increase fuel efficiency [1] and it has been subject to extensive studies in the past few decades. However, the lack of direct control on the auto-ignition process and relatively narrow operation range inhibit the practical application of this low temperature high efficient combustion mode [2]. In order to enhance the control of auto-ignition and extend the operation range of CAI combustion, spark ignition (SI) was used to assist CAI combustion. In this case, the early flame propagation induced by spark discharge could effectively control the later autoignition [3, 4]. In addition, this hybrid combustion mode could be used to bridge pure SI mode and CAI mode during mode transition when applying to the full load operations in the practical engine $[\underline{2}, \underline{5}, \underline{6}, \underline{7}, \underline{8}$. However, the recent study on the SI-CAI hybrid combustion indicated the existence of significant cycle-to-cycle variation (CCV) during mode transition $[\underline{8}, \underline{9}, \underline{10}, \underline{11}]$.
In the SI-CAI hybrid combustion, the flame propagation is mainly controlled by the transport of heat and active species in the flame front and distorted by the in-cylinder turbulence [12]. The variation of the early flame propagation would in turn affect the later auto-ignition process [13]. The premise of controlling and stabling SI-CAI hybrid combustion is to effectively manage the early flame propagation process. The local fuel/air equivalence ratio around the spark plug significantly affects the spark kernel formation and flame propagation process in spark ignition engine. Persson et al. [14] used high speed fuel Planar Laser-Induced Fluorescence (PLIF) to study the effect of fuel stratification on spark assisted compression ignition (SACl) with ethanol as fuel. They found the lower fuel concentration in the vicinity of the spark plug decreased the flame expansion speed with the overall lean mixture (lambda 1.4). Middleton et al. [15] investigated the propagation of premixed laminar reaction fronts with different fuel/air equivalence ratios using transient one-dimensional flame simulations and indicated the increased flame burning velocity with the isooctane/air equivalence ratio increasing from 0.1 to 1.0. The experimental 
study performed by Benajes et al. [16] shows that the increase in the directly injected fuel mass has a positive effect on the assistance of the spark in the combustion process for both combustion stability and cycle to cycle control. Williams et al. [17] studied the in-cylinder fuel-air mixing distributions in a firing gasoline-direct-injection engine using PLIF imaging and indicated the reduced mean equivalence ratio around spark plug would increase the $0-10 \%$ mass fraction burned (MFB) duration. The previous studies demonstrated the significant effect of equivalence ratio on flame propagation process.

In order to form a desired fuel stratification, the appropriate direct injection strategy in combination with a suitable bowl piston is required $[\underline{18}, \underline{19}, \underline{20}]$. Mismatch between the piston bowl and injection timing would cause inappropriate fuel air mixing and lead to unstable combustion and increased emissions. Xu et al. [21] applied CFD modeling method to optimize piston shapes to form the rich fuel cloud around the spark plug in a GDI engine. The numerical simulations performed by Joh et al. [22] also demonstrated that piston shape had a strong influence on air-fuel interaction and the charge distribution around spark plug. The invention reported in [23] designed a combustion chamber including a bowl piston for a gasoline direct-injection controlled autoignition combustion engine. In addition to the piston shapes, the injection strategy also plays an important role on controlling in-cylinder fuel stratification patterns. Earlier injection timing increases fuel surface wetting, resulting in excessive engine out smoke, while later injection timing decreases available time for air-fuel mixing prior to the time of ignition [24]. The results reported in [25] showed that misfire occurred when the charge was either over-mixed and too lean to ignite in the spark plug region or over-penetrated and located away from the spark plug to the intake side of the chamber. The split injection strategies also showed significant influence on the fuel/air mixture cloud formation [26]. Persson et al. [14] proposed the combined injection strategy with both port fuel injection and direct injection to effectively form overall homogeneous mixture with appropriate fuel stratification around spark plug. The simultaneous injection using PFI injectors and DI injectors presented in [20] were able to improve the fuel/air mixture formation and resulted in reduced fuel consumption and torque fluctuations.

In the application of SI-CAI hybrid combustion, the relatively rich mixture around the spark plug is preferred to enhance the robustness of the early flame propagation. On the other hand, the diluted mixture in the outer region is preferred to control the heat release of auto-ignition. In order to effectively manage the fuel stratification, the combination of port fuel injection (PFI) and gasoline direct injection (GDI) is adopted in this study. The overall stoichiometric fuel/air mixture was applied to enable the emission reduction with the conventional three-way catalysts. In order to take advantage of the benefits provided by both PFI and GDI technology, the best matching between the spray and piston shapes is necessary to create appropriate fuel stratification pattern while providing adequate fuel around the spark plug to attain reliable ignition. The effect of bowl piston shapes and direct fuel injection strategies on the in-cylinder conditions, including flow conditions, fuel stratification patterns, thermal conditions and fuel evaporation ratios, is investigated in detail using three-dimensional computational fluid dynamics (3-D CFD) simulations. Three bowl piston shapes with different bowl depths, diameters and curvatures were designed and modelled in a single cylinder engine. The GDI ratios and direct injection timings were varied to investigate the effect of different injection strategies. A multi-hole injector was selected to perform the numerical study because of its superior performance and low cost [27, 28]. An engine operating load of IMEP=3.6 bar was selected to perform the simulations. The simulation results presented in this study clarified the effect of bowl piston shapes, $\mathrm{PFI} / \mathrm{GDI}$ fuel ratios and direct injection timings on the in-cylinder fuel stratification in a PFI/GDI gasoline engine. They would provide the fundamental knowledge and effective guidance on selecting the optimal bowl piston shape and fuel injection strategy to stabilize the SI-CAI hybrid combustion in the future experimental investigations.

\section{METHODOLOGY}

\section{Numerical Models And Validation}

In this study, the commercial CFD software STAR-CD ${ }^{\text {TM }}$ was adopted to perform the simulations. A set of models, including MPI2 nozzle model [29], Reitz-Diwakar atomization and breakup model [30], were employed to simulate the fuel spray process. The O'Rourke model and Bai model [31] were adopted to consider the inter-droplet collision and wall impingement. Reynolds-Averaged Navier Stokes (RANS) approach was applied with RNG k- $\varepsilon$ turbulence model in the simulations. Pressure-Implicit with Splitting of Operators (PISO) algorithm was used to solve the equations. The heat transfer was implemented through the general form of the enthalpy conservation equation for the fluid mixture [32]. The Angelberger wall function [33] was used for the simulation of the wall heat transfer.

A multi-hole injector was selected in this study because of its superior performance and low cost [27, 28]. The optical visualizations of the spray plume in a constant volume vessel were performed to validate the spray models. The optical measurements were carried out using Schlieren method [34]. The injection pressure and fuel temperature were $10 \mathrm{MPa}$ and $293 \mathrm{~K}$. The background pressure and temperature were 0.1 $\mathrm{MPa}$ and $293 \mathrm{~K}$. The detailed procedure of the measurement could be found in [34].

In the simulation, a fine mesh with 1, 140, 000 grids with $1.5 \mathrm{~mm}$ grid size was adopted. The time step in the simulation was 0.005 $\mathrm{ms}$. The parameters of the adopted models were adjusted to reproduce the spray measurements. Figure 1 compares the liquid droplets image of the spray plume from optical measurements and simulations. The spray liquid tip penetration is shown in Figure 2. The results show reasonable agreement between the modelled spray and the measurements. 


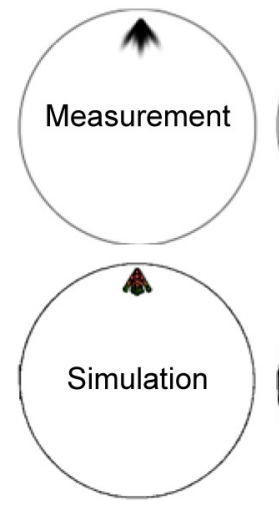

$\mathrm{t}=0.6 \mathrm{~ms}$
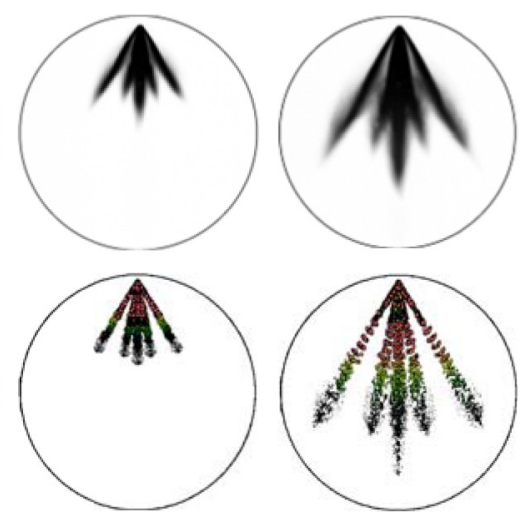

$\mathrm{t}=1 \mathrm{~ms}$

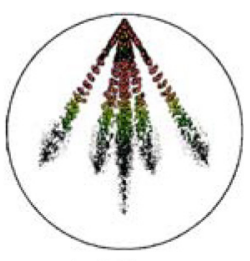

$\mathrm{t}=1.8 \mathrm{~ms}$
Figure 1. The spray plume from optical measurement and simulations.

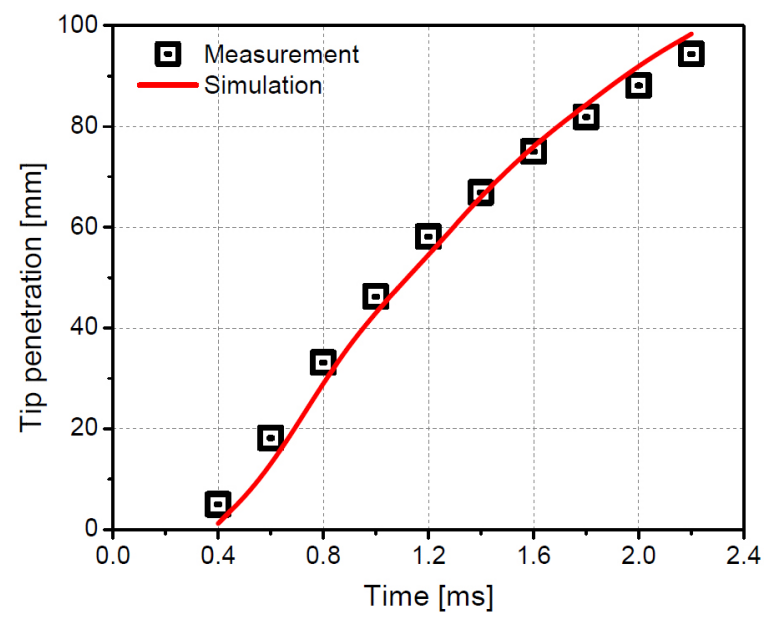

Figure 2. The spray liquid tip penetration from measurement and simulation.

\section{Piston Shapes Design}

In this study, different piston shapes were designed from the origin flat piston in a single cylinder engine [2]. The engine specifications are given in Table 1 . The engine comprises a Ricardo Hydra single cylinder block and a specially designed cylinder head, which is equipped with a 4-variable valve actuation system (4VVAS) with BMW's Vanos and Valvetronics on both the intake and exhaust camshafts. The engine enables both port fuel injection (PFI) and gasoline direct injection (GDI) with one injector mounted in the intake port and another direct injector mounted at the intake side.

Table 1. Engine specifications.

\begin{tabular}{|l|l|}
\hline Bore & $86 \mathrm{~mm}$ \\
\hline Stroke & $86 \mathrm{~mm}$ \\
\hline Displacement & $0.5 \mathrm{~L}$ \\
\hline Compression ratio & 10.66 \\
\hline Combustion chamber & Pent roof / 4 valves \\
\hline Fuel injection & PFI/GDI \\
\hline Fuel & Gasoline 93 RON \\
\hline Intake pressure & Naturally aspirated \\
\hline Throttle & WOT \\
\hline
\end{tabular}

Figure 3 shows the newly designed bowl pistons. In order to maintain the compression ratio, boss-shaped bodies were added on the flat piston for bowl pistons and different piston bowls were then cut from the boss-shaped bodies. Compared to Piston A, Piston B has lager bowl diameter. Piston A and B have been manufactured and ready for engine tests. Basing on Piston A and B, a deeper piston bowl was designed in Piston C.

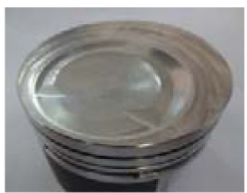

Piston A

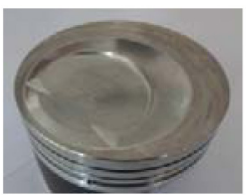

Piston B

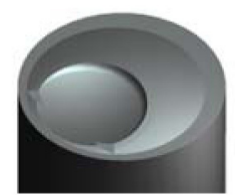

Piston C
Figure 3. Newly designed bowl pistons.

\section{Case Setup}

The moving meshes for flat piston, Pistons A, B and C were generated in ES-ICE using the mapping method. The engine mesh with Piston A is shown in Figure 4 as an example. All the four meshes have similar grid size (around $0.8 \mathrm{~mm}$ ). In order to systematically evaluate the effect of piston shapes and fuel injection strategies on the in-cylinder conditions, an engine operating load of IMEP=3.6 bar was selected to perform the simulations. Table 2 shows the specific operation conditions. The stable SI-CAI hybrid combustion was achieved by utilizing both external exhaust gas recirculation (EGR) and internal EGR achieved by the negative valve overlapping (NVO) strategy. It should be noted that the residual gas fraction (RGF) before the combustion shown in Table 2 includes both internal and external exhaust gases and was estimated by the corresponding one-dimensional simulations based on GTpower. A large amount of residual gas was used to dilute the combustion process and lower the combustion temperature to achieve high thermal efficiency and low NOx emission. The other experimental detail could be found in reference [] $]$ and [13].

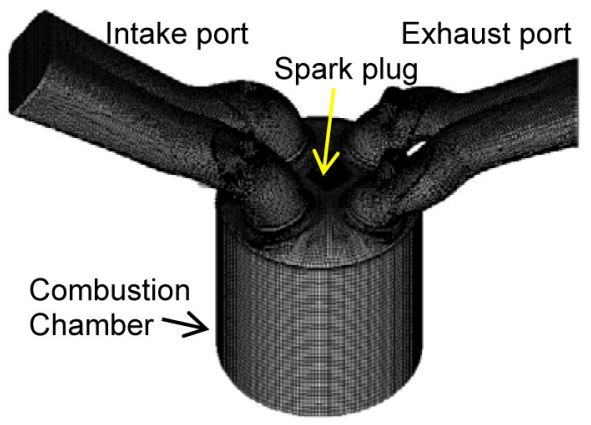

Figure 4. Engine mesh with Piston A. 
Table 2. Operation conditions.

\begin{tabular}{|l|l|}
\hline Indicated mean effective pressure (IMEP) & $3.6 \mathrm{bar}$ \\
\hline Exhaust valve open (EVO) & $177^{\circ} \mathrm{CA}$ ATDC \\
\hline Exhaust valve close (EVC) & $254^{\circ} \mathrm{CA}$ ATDC \\
\hline Exhaust valve lift (EL) & $1.9 \mathrm{~mm}$ \\
\hline Intake valve open (IVO) & $494^{\circ} \mathrm{CA}$ ATDC \\
\hline Intake valve close (IVC) & $603^{\circ} \mathrm{CA}$ ATDC \\
\hline Intake valve lift (IL) & $5.0 \mathrm{~mm}$ \\
\hline Spark Timing & $685^{\circ} \mathrm{CA}$ ATDC \\
\hline Fueling Rate & $13.4 \mathrm{mg} / \mathrm{cycle}$ \\
\hline Lambda & 1 \\
\hline Residual gas fraction (RGF) & $40 \%$ \\
\hline Engine Speed & $1500 \mathrm{r} / \mathrm{min}$ \\
\hline
\end{tabular}

Table 3. Simulation cases and computational conditions.

\begin{tabular}{|l|l|l|l|}
\hline Cases & Piston Type & GDI ratio & GDI SOI [ ${ }^{\circ}$ CA ATDC] \\
\hline F-0.35-680 & Flat Piston & 0.35 & 680 \\
\hline F-0.35-660 & Flat Piston & 0.35 & 660 \\
\hline F-0.35-640 & Flat Piston & 0.35 & 640 \\
\hline F-0.2-680 & Flat Piston & 0.2 & 680 \\
\hline F-0.2-660 & Flat Piston & 0.2 & 660 \\
\hline F-0.2-640 & Flat Piston & 0.2 & 640 \\
\hline A-0.35-680 & Piston A & 0.35 & 680 \\
\hline A-0.35-660 & Piston A & 0.35 & 660 \\
\hline A-0.35-640 & Piston A & 0.35 & 640 \\
\hline A-0.2-680 & Piston A & 0.2 & 680 \\
\hline A-0.2-660 & Piston A & 0.2 & 660 \\
\hline A-0.2-640 & Piston A & 0.2 & 640 \\
\hline B-0.35-680 & Piston B & 0.35 & 680 \\
\hline B-0.35-660 & Piston B & 0.35 & 660 \\
\hline B-0.35-640 & Piston B & 0.35 & 640 \\
\hline B-0.2-680 & Piston B & 0.2 & 680 \\
\hline B-0.2-660 & Piston B & 0.2 & 660 \\
\hline B-0.2-640 & Piston B & 0.2 & 640 \\
\hline C-0.35-680 & Piston C & 0.35 & 680 \\
\hline C-0.35-660 & Piston C & 0.35 & 660 \\
\hline C-0.35-640 & Piston C & 0.35 & 640 \\
\hline C-0.2-680 & Piston C & 0.2 & 680 \\
\hline C-0.2-660 & Piston C & 0.2 & 660 \\
\hline C-0.2-640 & Piston C & 0.2 & 640 \\
\hline & & & \\
\hline
\end{tabular}

In this study, the effects of piston bowl shapes and injection strategies on in-cylinder conditions were studied in motored operations. In the simulations, the inlet temperature and pressure were fixed at $355 \mathrm{~K}$ and $0.99 \mathrm{bar}$. The initial incylinder temperature and pressure were $571 \mathrm{~K}$ and 0.49 bar, respectively. These conditions were estimated by the corresponding one-dimensional simulations using GT-power. The wall temperature for cylinder head, piston head and cylinder liner were $400 \mathrm{~K}, 442 \mathrm{~K}$ and $371 \mathrm{~K}$ respectively. The CFD simulations were carried out from IVO to top dead centre
(TDC), including the direct injection process. The intake mixture prepared by the port fuel injection was set as the homogeneous fuel/air mixture. It should be noted that the overall in-cylinder equivalence ratio after direct injection for all cases was kept stoichiometric. Table 3 shows all the simulation cases and the corresponding computational conditions. The case name of "F-0.35-680" refers to the case with Flat Piston, a GDI ratio of 0.35 and a start of injection (SOI) of $680^{\circ} \mathrm{CA}$. The compression ratio was kept at 10.66 and the total incylinder mass after the direct injection was kept constant for all the cases studied.

\section{RESULTS AND DISCUSSION}

\section{In-Cylinder Flow Conditions}

Figure 5 shows evolution of the in-cylinder swirl ratio (SR), tumble ratio (TR) and cross tumble ratio (CTR) before injection. The equation used to calculate the swirl ratio is given as following [35]:

$$
\operatorname{SR}(\theta)=\frac{\sum_{i}^{m} v_{i}(\theta) r_{i}(\theta) V_{i}(\theta) \rho_{i}(\theta)}{\frac{2 \pi n}{60} \sum_{i}^{m} r_{i}(\theta)^{2} V_{i}(\theta) \rho_{i}(\theta)}
$$

where $n$ is engine speed, $\theta$ the crank angle, $i$ the cell number, $v_{i}(\theta)$ the cell volume, $\rho_{i}(\theta)$ the cell density, $v_{i}(\theta)$ and $r_{i}(\theta)$ are the tangential velocity and radius respectively in the cylindrical coordinate with $z$ axis as the swirl axis. With the same method, the swirl axis along with the cylindrical coordinate system in Equation (1) is then replaced as the tumble/cross tumble axis to evaluate TR/CTR. The tumble/cross tumble axis is parallel to $y / x$ axis and crosses the central point between maximum and minimum $z$ value of the combustion chamber.

For simplicity, Figure 5 only compares the cases with GDI ratio $=0.35$. As expected, the newly designed piston shapes have little effect on the intake process, indicating any modification of the in-cylinder conditions would only come from the interactions between spray jets and piston shapes.

In order the reveal spatially resolved in-cylinder conditions the cylinder volume is divided into seven cylindrical zones as shown in Figure 6. In addition, a Spark Zone is defined as a spherical volume of $20 \mathrm{~mm}$ in diameter around spark plug.

It has been found that the high mean flow velocities and turbulence levels can shorten combustion duration in the lean mixtures [36]. Figures 7 and $\underline{8}$ show the mean flow velocity magnitudes $(\mathrm{Vm})$ of the whole combustion chamber and Spark Zone respectively. Overall, large GDI ratio increases the in-cylinder flow velocity at all injection timings. As the injection timing is advanced, the effect of piston shape is weakened. The mean velocity magnitudes are similar for different piston shapes at $\mathrm{SOI}=660^{\circ} \mathrm{CA}$ and $640{ }^{\circ} \mathrm{CA}$. In addition, the relatively 
higher mean Vm in cases with GDI ratios of 0.35 decreases fast and almost approach the cases with GDI ratio of 0.2 at TDC. Although the effect of the piston shapes seems not very significant for the mean flow velocity of the whole combustion chamber, especially for the cases with early injection timings, the velocity around the spark plug changes significantly as shown in Figure 8. Flat piston and Piston $\mathrm{C}$ show the lowest velocity magnitudes, while Piston $A$ and $B$ show comparatively stronger flow around the spark plug after the injection. Similarly, the larger GDI injection ratio would apparently increase the velocity magnitudes around the spark plug. However, the differences of the $\mathrm{Vm}$ among cases with $\mathrm{SOI}=660^{\circ} \mathrm{CA}$ and $640^{\circ} \mathrm{CA}$ are decreasing with the piston ascending.

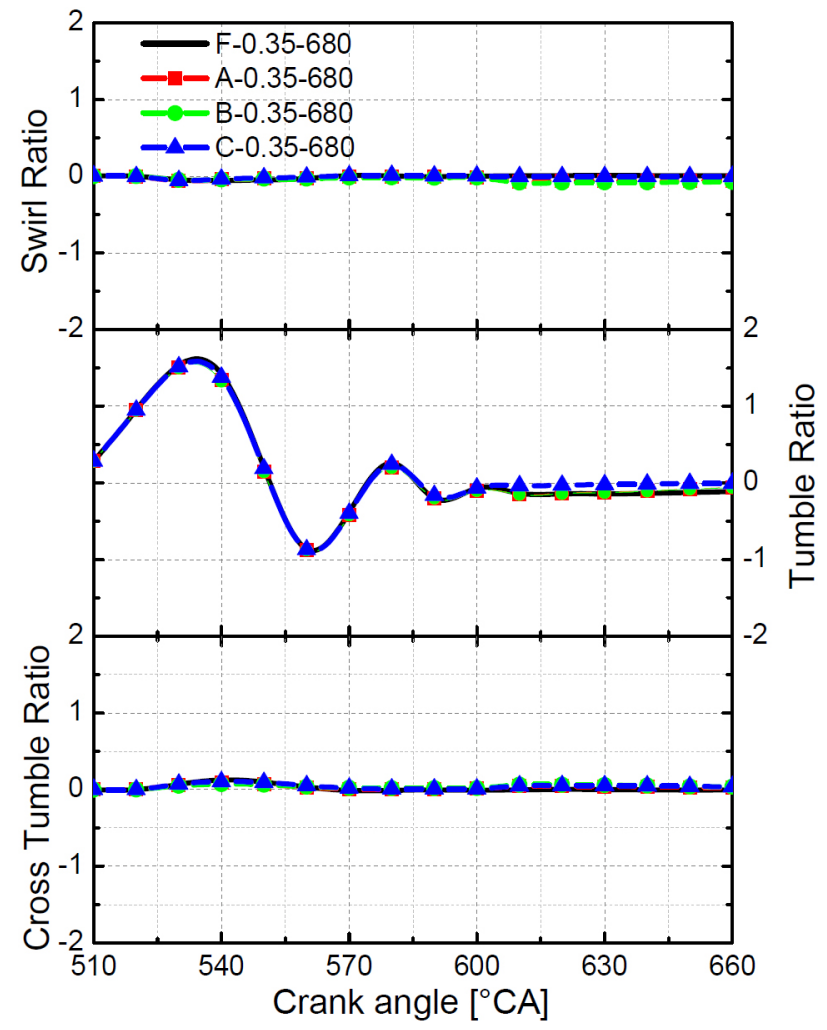

Figure 5. Evolution of in-cylinder swirl ratio (SR), tumble ratio (TR) and cross tumble ratio (CTR) before injection.

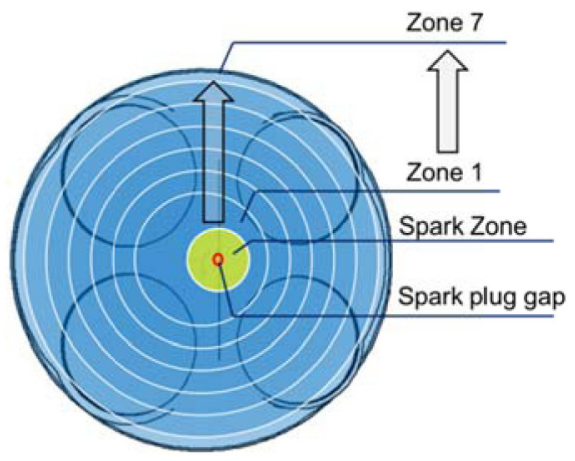

Figure 6. Schematic of the zones defined to reveal the in-cylinder zone-to-zone conditions.

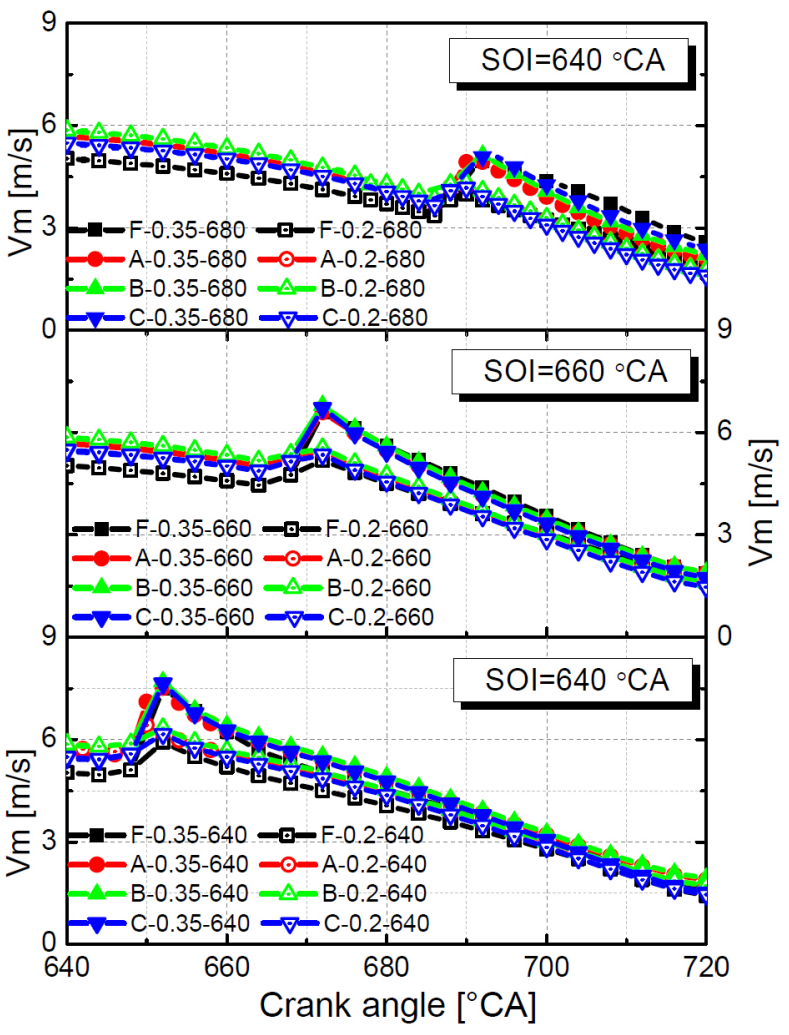

Figure 7. Mean flow velocity magnitudes of the whole combustion chamber.

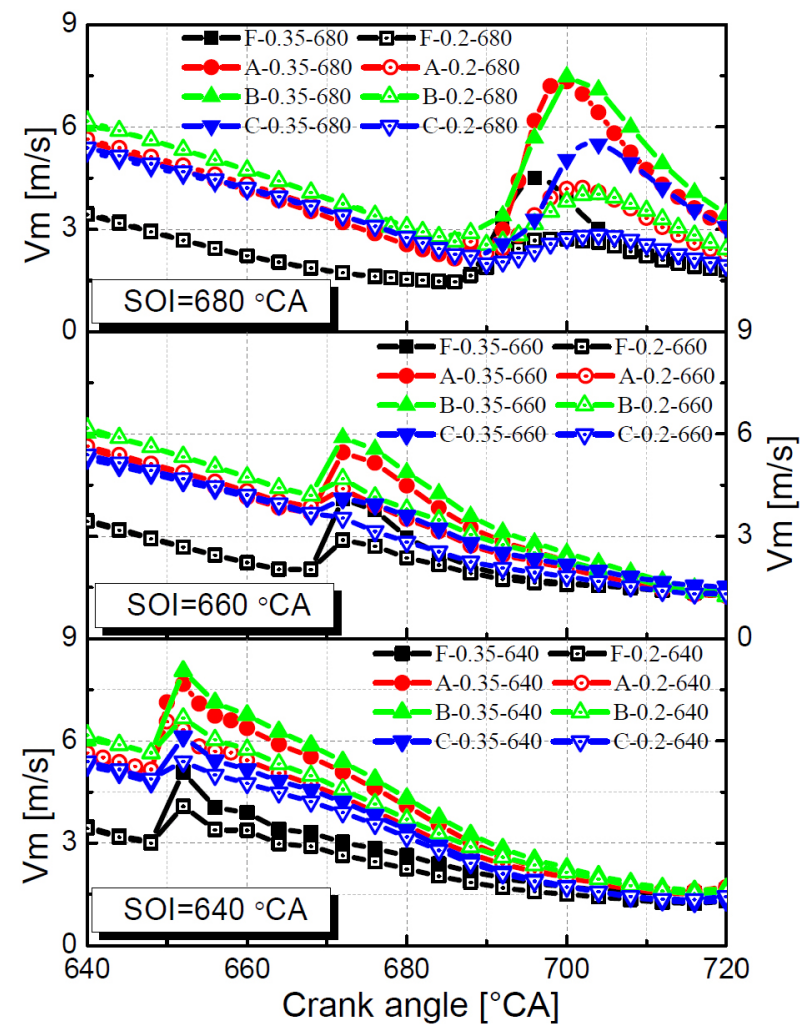

Figure 8. Mean flow velocity magnitudes of the Spark Zone. 
Figures 9 and $\underline{10}$ compare the velocity vectors and magnitudes distributions at $700{ }^{\circ} \mathrm{CA}$ in the cross section through the central axis of the cylinder. The injector is on the intake side on the left. It should be noted that the contour scales used for different injection timings in Figures 9 and $\underline{10}$ are different. Generally, the later $\mathrm{SOI}$ is, the higher the local maximum velocity magnitude is. It can be seen that the spray tip has highest velocity. With the Flat Piston, the high velocity region is distributed near the piston surface. The designed bowl pistons cause significant impact on the in-cylinder flow distribution. The late injection ( $\mathrm{SOI}=680^{\circ} \mathrm{CA}$ ) would generate an apparent tumble near the spark plug and guide the fuel tip to the spark plug, as indicated by the black arrows in the first column of Figure 9 and Figure 10. As discussed in the next section, the production of such tumble flow assists the formation of the rich mixture around the spark plug. The advanced injection strategies ( $\mathrm{SOI}=660^{\circ} \mathrm{CA}$ and $640^{\circ} \mathrm{CA}$ ) cause spray jets away from the designed piston bowl and generate a tumble flow structure at the exhaust side. By comparing Figure 10 to Figure $\underline{9}$, it can be seen that the reduced GDI ratio would decrease the spray momentum and weaken the in-cylinder flow.

Flat
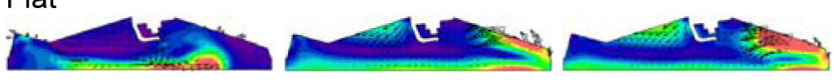

Piston A

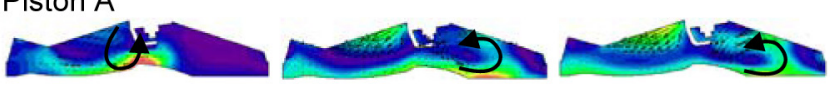

Piston B
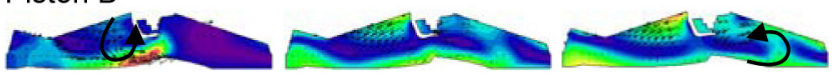

Piston C
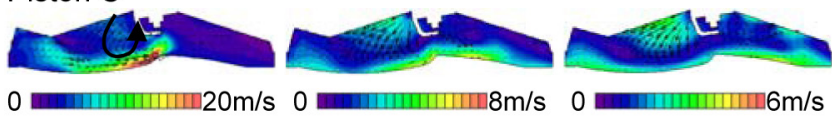

$\mathrm{SOI}=680^{\circ} \mathrm{CA}$

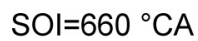

$\mathrm{SOI}=640^{\circ} \mathrm{CA}$

Figure 9. Cross-section views of in-cylinder velocity vectors and magnitudes at $700^{\circ} \mathrm{CA}$ with $\mathrm{GDI}$ ratio $=0.35$.

In general, Pistons A and B could generate higher velocity magnitudes, while large GDI ratio is preferred to further increase the $\mathrm{Vm}$ around the spark plug. Therefore, it could be concluded that the shallow bowl piston shape could improve the local velocities around the spark plug, which would enhance the early flame propagation in the SI-CAI hybrid combustion.

Figures 11 and 12 show the average turbulence kinetic energy (TKE) of the whole combustion chamber and that of the Spark Zone, respectively. Compared to the Flat Piston, the bowl pistons could effectively increase the average TKE level of the whole combustion chamber. But the differences in the average TKE between different bowl pistons are not significant. Similarly, a larger GDI ratio generates higher TKE at all injection timings. Piston $\mathrm{C}$ generates a little higher TKE compared to that of Pistons $\mathrm{A}$ and $\mathrm{B}$ with $\mathrm{SOI}=680^{\circ} \mathrm{CA}$. The average TKE values of the Spark Zone among cases are different as shown in Figure 12. Pistons A and B generate higher TKE in the Spark Zone at different injection timings and GDI ratios. Piston $A$ is characterized with the highest TKE value of $53.6 \mathrm{~m}^{2} / \mathrm{s}^{2}$ at $700{ }^{\circ} \mathrm{CA}$ with SOI $=680{ }^{\circ} \mathrm{CA}$ and GDI ratio $=0.35$.

Flat
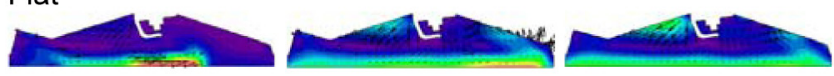

Piston A
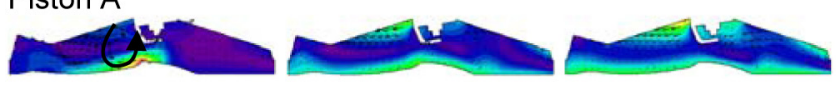

Piston B
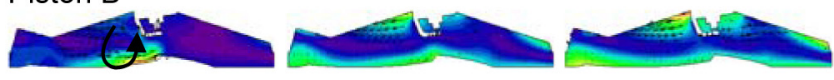

Piston $\mathrm{C}$

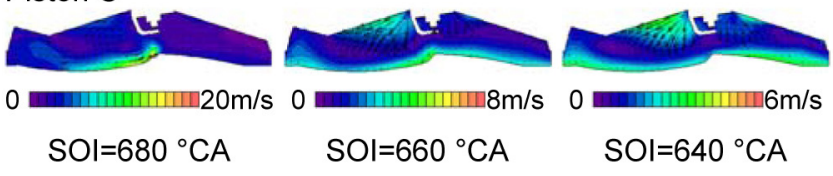

Figure 10. Cross-section views of in-cylinder velocity vectors and magnitudes at $700{ }^{\circ} \mathrm{CA}$ with $\mathrm{GDI}$ ratio $=0.2$.

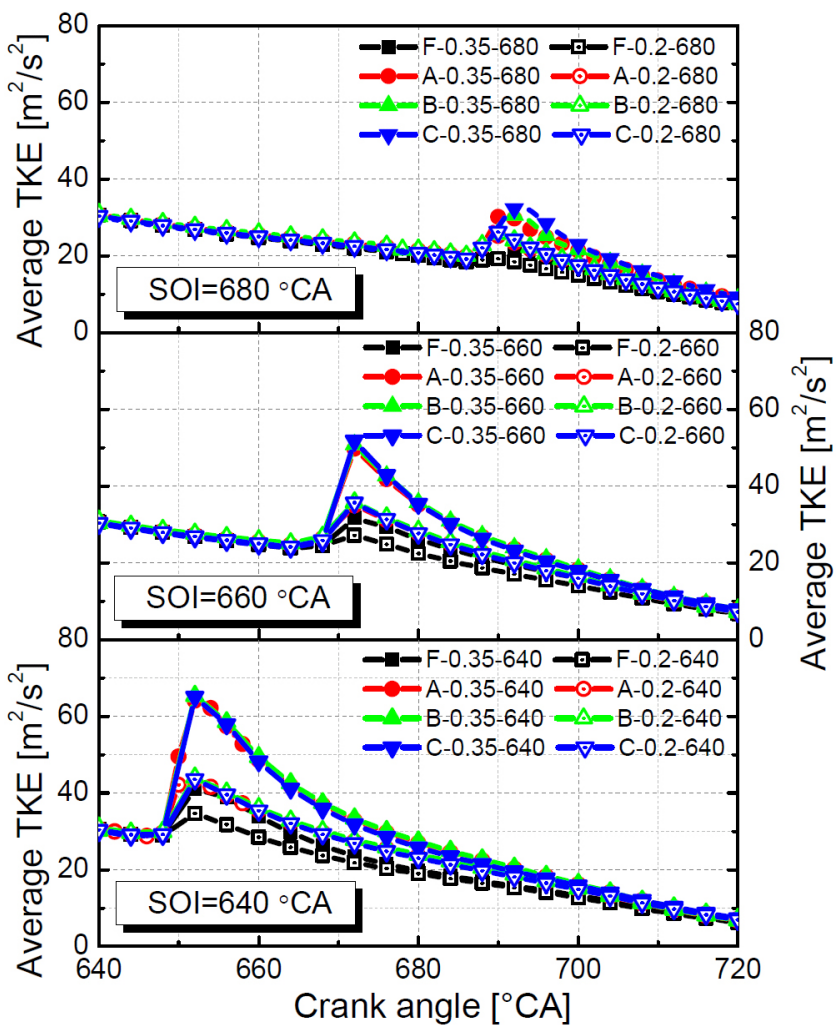

Figure 11. Average TKE of the whole combustion chamber. 


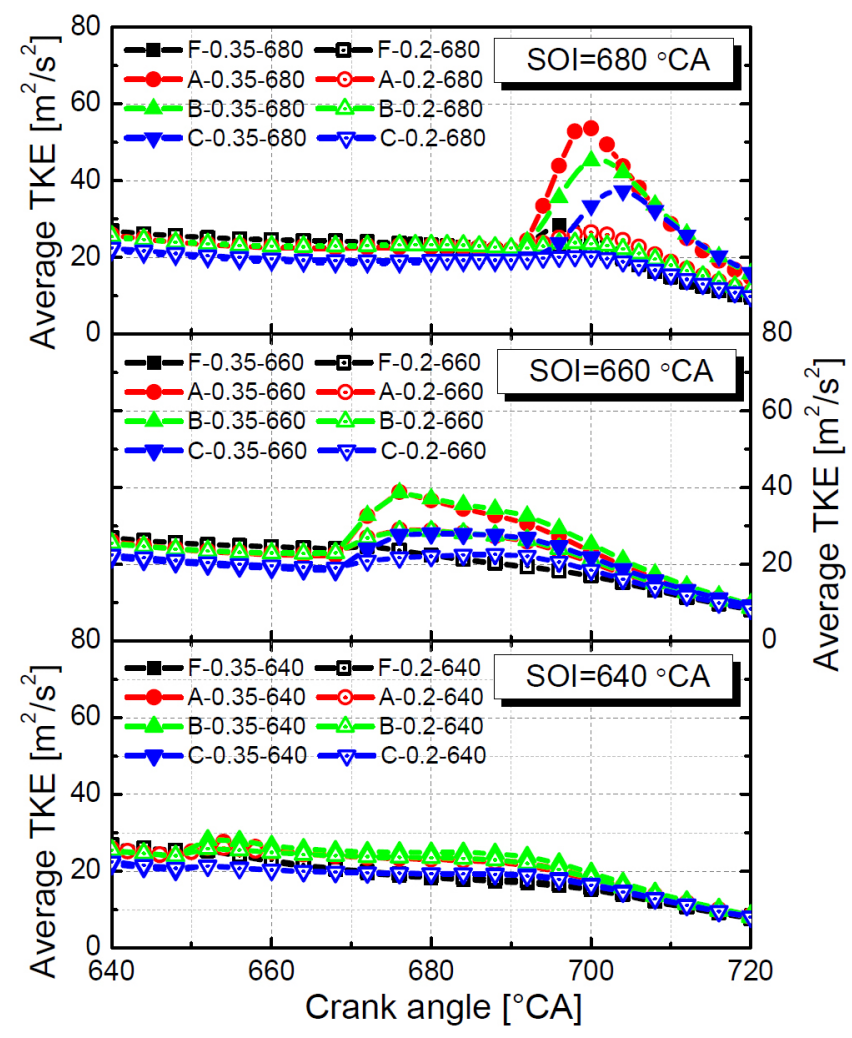

Figure 12. Average TKE of the Spark Zone.

Figures 13 and 14 show the TKE distributions among cases at $700{ }^{\circ} \mathrm{CA}$. It can be seen that the higher TKE region is located at the exhaust valve side with the Flat Piston. Although the overall TKE at $700{ }^{\circ} \mathrm{CA}$ significantly decreased as the direct injection timing is advanced, both pistons $A$ and $B$ generate the highest TKE region at the chamber centre, which is beneficial to stabilize the flame propagation. The highest TKE is produced in case A-0.35-680 just underneath the spark plug, resulting in the highest TKE in the Spark Zone as shown in Figure 12. It can be seen in Figure 14 that the reduced GDI ratio significantly decreases TKE level, while Piston A still generates high TKE region near spark plug and creates highest TKE of Spark Zone as shown in Figure 12. In the case of the deepest piston bowl (case C-0.2-680), the high TKE region is inside the bowl, leading to relatively low TKE around spark plug.

\section{Flat}
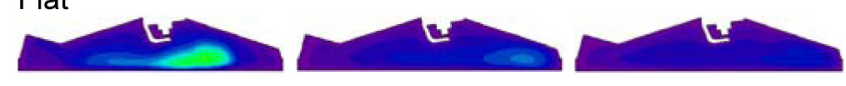

Piston A
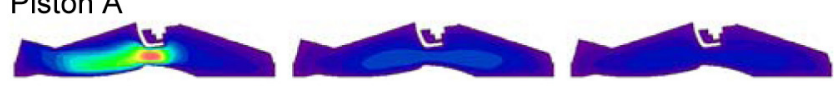

Piston B
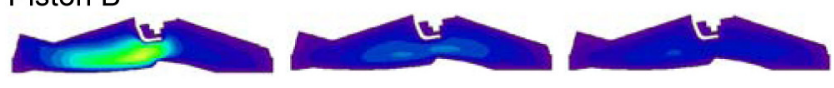

Figure 13.

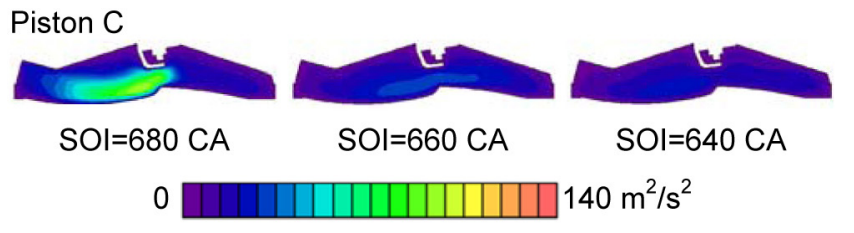

Figure 13. (cont.) Cross-section views of TKE distributions at $700{ }^{\circ} \mathrm{CA}$ with $\mathrm{GDI}$ ratio $=0.35$.

Flat
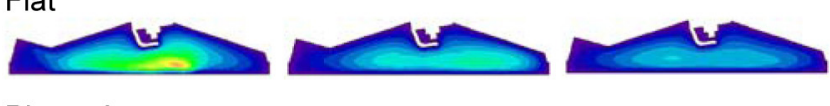

Piston A

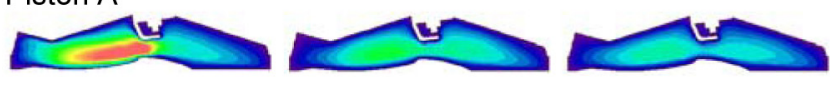

Piston B

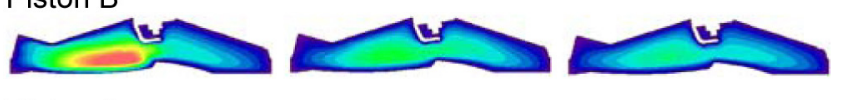

Piston $\mathrm{C}$

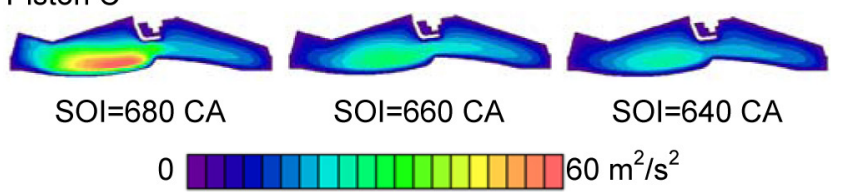

Figure 14. Cross-section views of TKE distributions at $700{ }^{\circ} \mathrm{CA}$ with GDI ratio $=0.2$.

The relative high flow $\mathrm{Vm}$ and TKE around spark plug would enhance the development of flame propagation. From this aspect, Piston $A$ and $B$ are superior to enhance the stable SICAI hybrid combustion, while the later injection strategy is preferable.

\section{Fuel Stratifications}

Figure 15 shows the fuel/air equivalence ratio of the Spark Zone. The designed bowl piston shapes could effectively enrich the mixture near the spark plug compared to the origin Flat Piston. The difference in equivalence ratios in the Spark Zone caused by different piston shapes are especially apparent with $\mathrm{SOI}=680{ }^{\circ} \mathrm{CA}$. Specifically, Piston A has the strongest capacity to guide the fuel to the spark plug. However, the larger GDI ratio leads to an over-rich mixture, forming smoke emission [25]. In contrast, the smaller GDI ratio of 0.2 produces more suitable equivalence ratio around the spark plug with $\mathrm{SOI}=680{ }^{\circ} \mathrm{CA}$. With $\mathrm{SOI}=660^{\circ} \mathrm{CA}$, Piston B could maintain the relatively rich mixture (equivalence ratio around 1.2) around the spark plug until TDC. Further advance in the direct injection timing to $\mathrm{SOI}=640{ }^{\circ} \mathrm{CA}$ could not produce the enrichment in the spark zones.

Figures 16 and 17 show the cross-section views of equivalence ratio distributions. In Figure 16 (GDI ratio=0.35), the rich region gradually moves to the exhaust side with the injection timing advancing. For the Flat Piston, the rich mixture locates at the exhaust side due to the lack of the guidance by the piston design. In the cases of pistons with bowls, a rich mixture around the spark plug is forming with the later injections. As the injection timing is advanced, some spray jets would miss the piston bowl and penetrate to the exhaust side. 
Figure 18 shows the in-cylinder spray patterns at $10{ }^{\circ} \mathrm{CA}$ after the start of injection with Piston $A$. The spray jets are divided into three groups from top to bottom G1, G2 and G3. With the later injection of $\mathrm{SOI}=680^{\circ} \mathrm{CA}$ (case A-0.35-680), all the spray jets would be contained and effectively guided by the piston bowl. With the more advanced injection timing of $\mathrm{SOI}=660$ ${ }^{\circ} \mathrm{CA}, \mathrm{G} 1$ sprays miss the piston bowl, while $\mathrm{G} 2$ sprays are towards the back of piston bowl. Further advance in SOI causes all spray jets away from the piston bowl. The above analyses illustrate the underlying causes of the resulting mixture distribution around the spark plug shown in Figures 16 and $\underline{17}$.

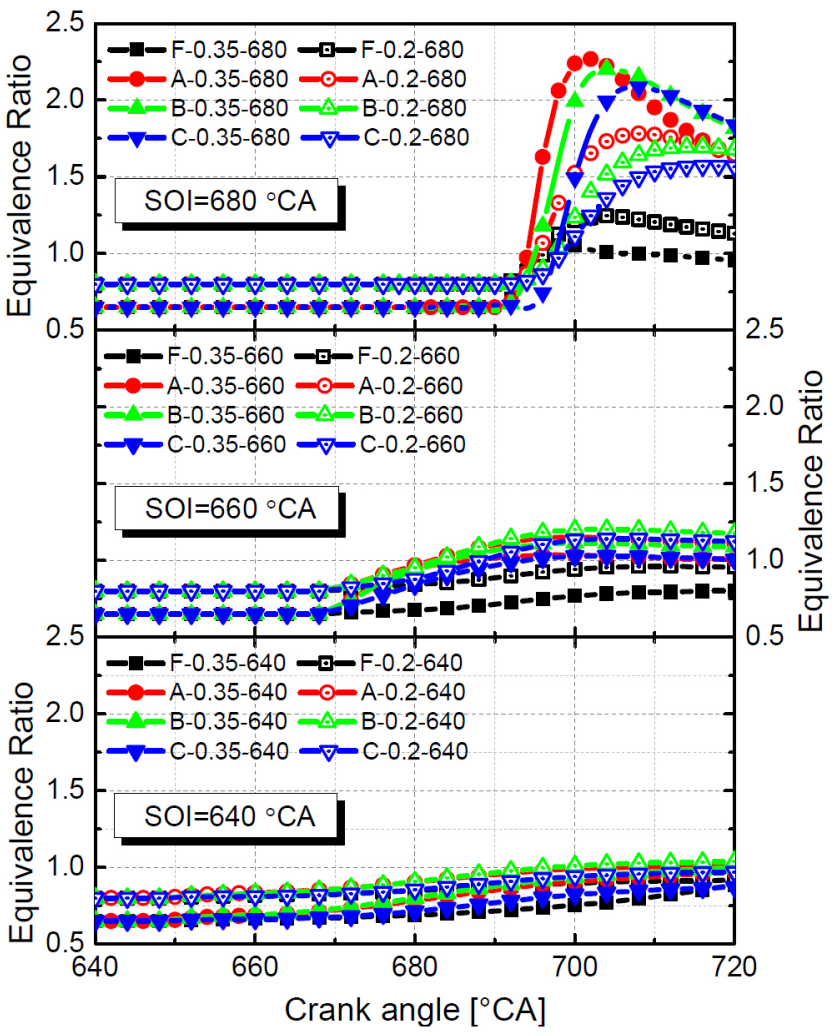

Figure 15. Average equivalence ratio of Spark Zone.

Flat
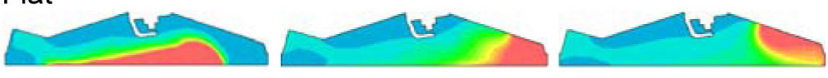

Piston A
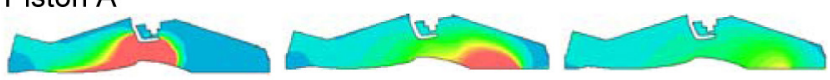

Piston B
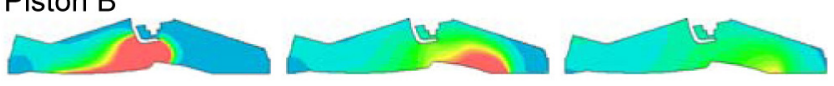

Piston C
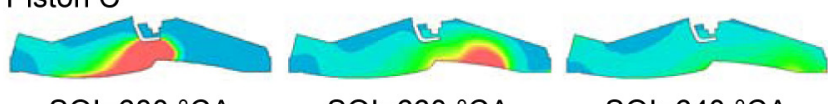

$\mathrm{SOI}=680^{\circ} \mathrm{CA}$

$\mathrm{SOI}=660^{\circ} \mathrm{CA}$

$\mathrm{SOI}=640{ }^{\circ} \mathrm{CA}$

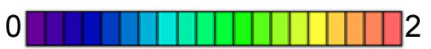

Figure 16. Cross-section views of equivalence ratio distributions at 700 ${ }^{\circ} \mathrm{CA}$ with GDI ratio $=0.35$.
Flat
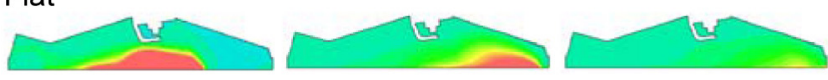

Piston A
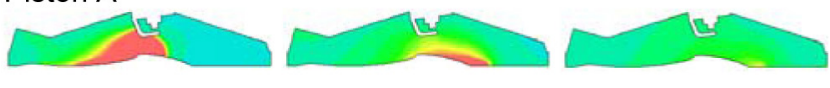

Piston B
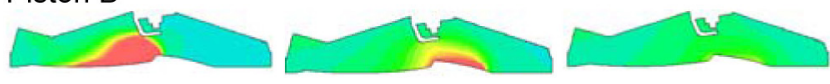

Piston C

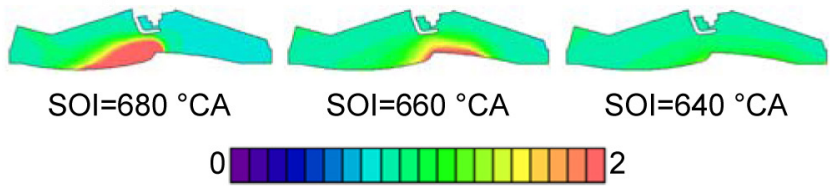

Figure 17. Cross-section views of equivalence ratio distributions at 700 ${ }^{\circ} \mathrm{CA}$ with $\mathrm{GDI}$ ratio $=0.2$.
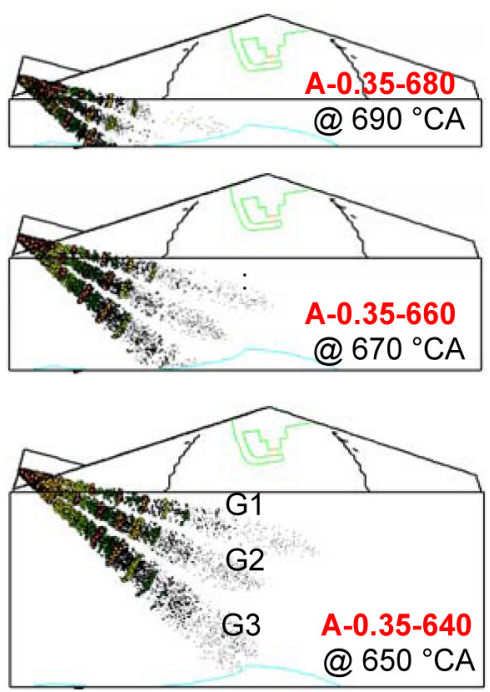

Figure 18. In-cylinder spray patterns for Piston A with different injection timings.

Figure 19 shows the duration of the spark window ( $z$ axis) during which the equivalence ratio of the mixture in the Spark Zone is between 1 and 1.5 and the corresponding averaged equivalence ratio (diameter of the ball). It should be noted that the cases with the equivalence ratio range outside 1 1.5 are excluded in Figure 19. It can be seen that the Flat Piston could only produce appropriate spark window with very late injection $\left(\mathrm{SOI}=680^{\circ} \mathrm{CA}\right.$ ). Pistons $\mathrm{A}$ and $\mathrm{B}$ could both generate appropriate spark window even with much earlier injection timing $\left(\mathrm{SOI}=640^{\circ} \mathrm{CA}\right)$. In particular, Piston B shows wider durations and higher average equivalence ratios. Piston $C$ could generate appropriate spark window with $\mathrm{SOI}=660^{\circ} \mathrm{CA}$. For the bowl pistons, the later injection $\left(\mathrm{SOI}=680^{\circ} \mathrm{CA}\right)$ could only generate very narrow spark windows although the average equivalence ratios are very high for some cases (e.g. case C-0.35-680). Overall, a lower GDI ratio (green balls) has more potential to extend the appropriate spark window. 


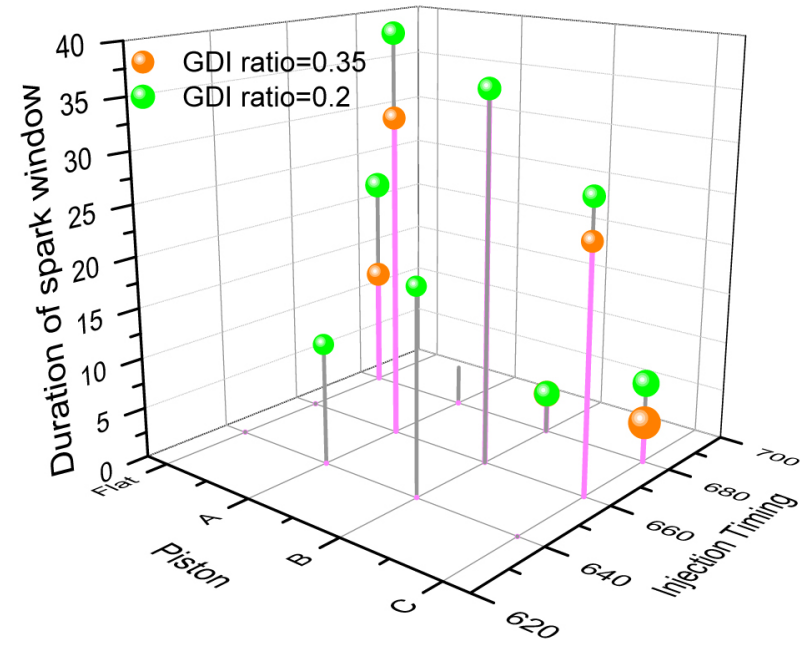

Figure 19. Duration of spark window (z axis) during which the equivalence ratio of Spark Zone is between 1 and 1.5 and the corresponding averaged equivalence ratio (diameter of the ball) for different piston shapes and injection timings.

\section{Thermal Conditions}

The spray and atomization process would affect in-cylinder mixture temperature which would impact the subsequent combustion process. As shown in Figure 20, the later injection (SOI $=680^{\circ} \mathrm{CA}$ ) would bring about noticeable differences in the average temperature of the Spark Zone. The rich mixture is associated with more significant evaporation of local fuel droplets, therefore there is a larger drop in case A-0.35-680. A smaller GDI ratio is preferable to maintaining a relatively high thermal state around the spark plug, as shown in Figure 20. It could be concluded that the inappropriate injection strategies (e.g. A-0.35-680) would leads to an over-rich mixture and lower charge temperature deteriorating the spark ignition and early flame propagation process. Compared to the over-rich mixture (equivalence ratio $>1.5$ ) with cooled charge temperature around spark plug, a relative rich fuel/air mixture with the equivalence ratio of 1 1.5 and high charge temperature around spark plug is thought to be more preferable for a reliable combustion. For the early injection cases (SOI=660 and 640 ${ }^{\circ} \mathrm{CA}$ ), the temperature evaluations of the Spark Zone are similar for all cases. For simplicity, these results are not shown here.

Figure 21 shows the zone-to-zone temperature distributions with $\mathrm{GDI}$ ratio $=0.2$. It is found that the cases with higher temperature central zones have relatively lower temperature in the outer zones, e.g. case C-0.2-680. Apart from the Spark Zone, the temperature profiles are independent of the piston shapes. In the case B-0.2-640 with early injection, the temperature gradually decreases from central zone to the outer zones, which could be beneficial to the formation of flame kernel and slowing down the heat release rate of auto-ignition combustion away from the spark plug. The temperature stratification in case B-0.2-640 is mainly attributed to the fuel stratification and evaporation process. Figure 22 shows the temperature distributions from vertical and horizontal angles at $700^{\circ} \mathrm{CA}$. With the injection timing advancing, the low temperature region gradually move from the central zone to the exhaust side, meanwhile the temperature of the outer zone shows decreasing trend. This explains the temperature distribution profiles of case B-0.2-640 in Figure 21. Figure 22 also demonstrates the large GDI ratio (i.e. 0.35) would create an over-low temperature region around spark plug, which is not good for early flame propagation.

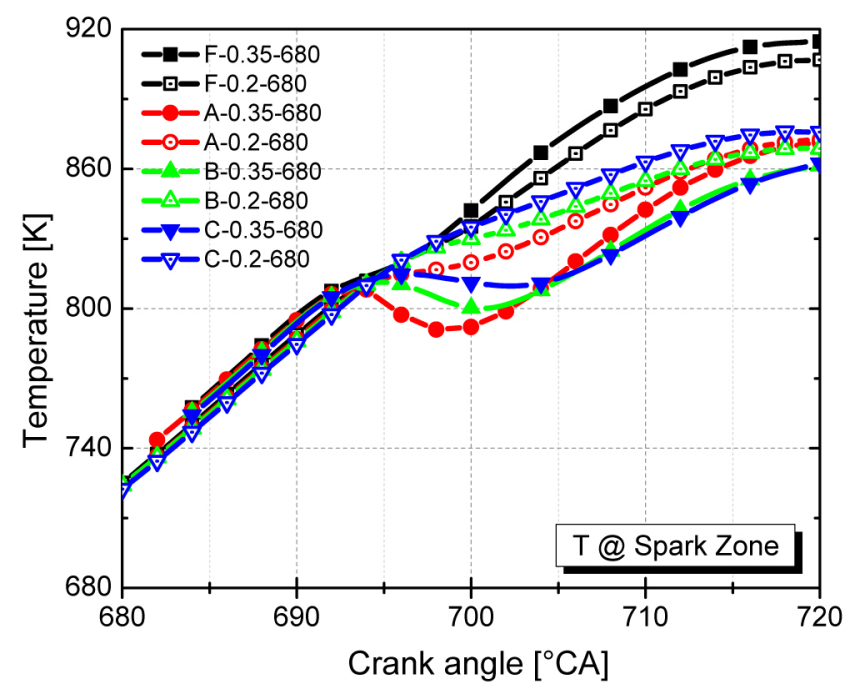

Figure 20. Average temperature of Spark Zone with $\mathrm{SOI}=680^{\circ} \mathrm{CA}$.

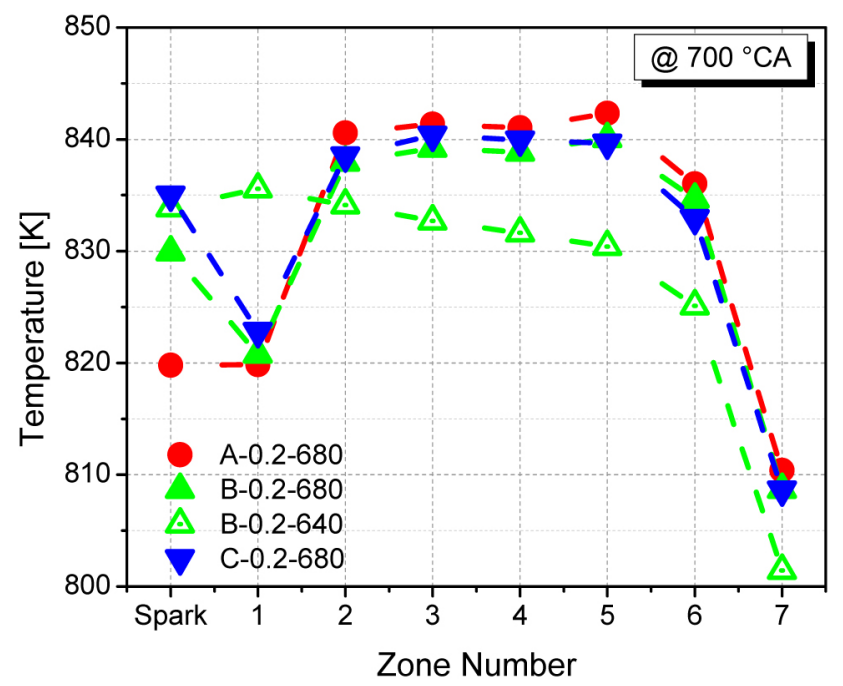

Figure 21. Zone-to-zone temperature distributions of different bowl piston shapes with GDI ratio $=0.2$ at $700{ }^{\circ} \mathrm{CA}$. 


\section{GDI ratio $=0.35$}
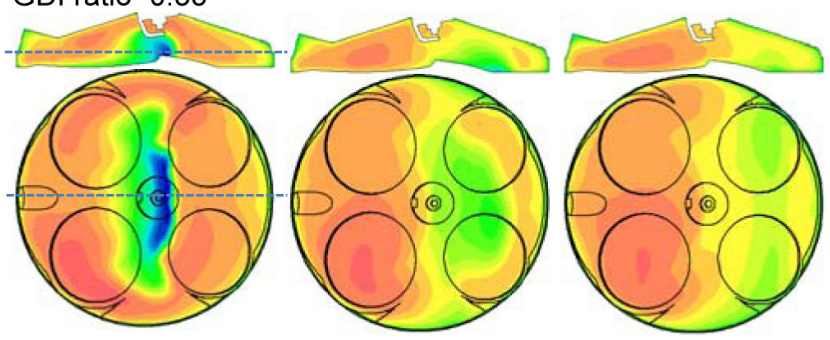

GDI ratio $=0.2$

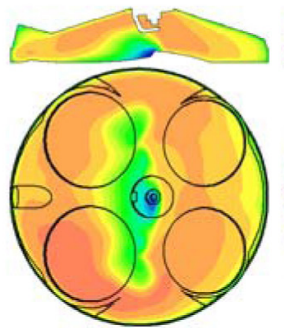

$\mathrm{SOI}=680^{\circ} \mathrm{CA}$

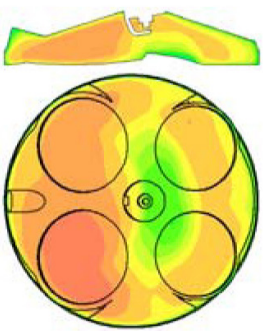

$\mathrm{SOI}=660^{\circ} \mathrm{CA}$

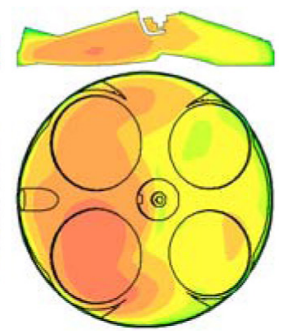

$\mathrm{SOI}=640^{\circ} \mathrm{CA}$

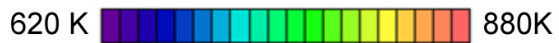

Figure 22. Cross-section views of temperature distributions of Piston B at $700{ }^{\circ} \mathrm{CA}$ with $\mathrm{GDI}$ ratio $=0.35$ and 0.2 .

\section{Fuel Evaporation Ratios}

Figure 23 shows the fuel evaporation ratio at $720^{\circ} \mathrm{CA}$ for all cases. The fuel evaporation ratio is defined as the ratio between the evaporated direct injection fuel mass and the total direct injection fuel mass. Generally, a large GDI ratio would increase the fuel evaporation ratio. The increased flow velocity and turbulence ratio caused by increased fuel momentum in these cases with a large GDI ratio would enhance the mixing between fuel and air and increase the fuel evaporation ratio. With the delayed injection timing, the evaporation ratio gradually decreases because of reduced duration for the mixing between fuel and air. In addition, the differences of the evaporation ratios caused by piston shapes are more significant with the late injection timing. Generally, Piston C shows highest evaporation ratio for all injection timings and GDI ratios. The evaporation ratios of Piston A and $B$ are comparable with that of origin Flat Piston.

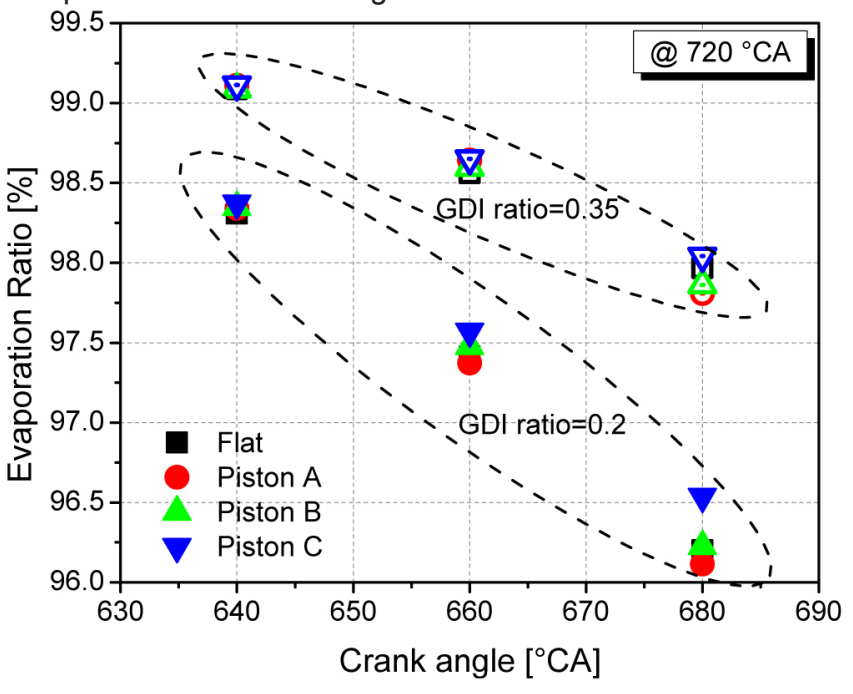

Figure 23. Fuel evaporation ratios at $720^{\circ} \mathrm{CA}$.

\section{SUMMARY/CONCLUSIONS}

In order to optimise the SI-CAI hybrid combustion, a combination of PFI and GDI is proposed in this study to form a rich mixture around spark plug and the lean mixture in the outer region. 3D-CFD simulations are used to study the effect of piston bowl shapes and direct injection strategies on the in-cylinder conditions. The findings are summarized as follows.

1. The shallow bowl piston shape (Pistons A and B) could improve the local velocities around spark plug. The late injection ( $\mathrm{SOI}=680^{\circ} \mathrm{CA}$ ) would generate an apparent tumble near spark plug and guide the fuel tip to the spark plug. The reduced GDI ratio would decrease the spray momentum and weaken the in-cylinder flow.

2. The small bowl diameter piston (Piston A) shows significant improvement of the TKE around spark plug. The deep piston bowl (Piston C) results in the high TKE region into the piston bowl, leading to relatively low TKE around spark plug.

3. Piston B shows wider durations of appropriate spark window and higher average equivalence ratios. Overadvanced direct injection timing ( $\mathrm{SOI}=640{ }^{\circ} \mathrm{CA}$ in this study) causes some spray jets miss the piston bowl, leading to poor enrichment of mixture around the spark plug. A lower GDI ratio (0.2) could be used to increase the equivalence ratio around spark plug for these early injection cases, having more potential to extend the appropriate spark window.

4. Increased GDI ratio and late injection timing (e.g. case A-0.35-680 in this study) would lead to over-rich mixture and the significant local charge cooling effect around the spark plug, hindering the spark ignition and early flame propagation process. The early injection would make the temperature gradually decreases from central zones to the outer zones.

5. The evaporation ratios of Piston A and B are comparable with that of origin Flat Piston, while Piston $\mathrm{C}$ shows highest evaporation ratio. Increased GDI ratio and advanced injection timing could increase the fuel evaporation ratio.

\section{REFERENCES}

1. Li, J., Zhao, H., Ladommatos, N., and Ma, T., "Research and Development of Controlled Auto-Ignition (CAI) Combustion in a 4-Stroke Multi-Cylinder Gasoline Engine," SAE Technical Paper 2001-01-3608, 2001, doi:10.4271/2001-01-3608.

2. Zhang Y., Xie H., and Zhao H., "Investigation of SI-HCCl Hybrid Combustion and Control Strategies for Combustion Mode Switching in a Four-Stroke Gasoline Engine," Combust. Sci. and Tech, 181:782-799, 2009.

3. Xie, H., Yang, L., Qin, J., Gao, R. et al., "The Effect of Spark Ignition on the CAI Combustion Operation," SAE Technical Paper 2005-01-3738, 2005, doi:10.4271/2005-01-3738.

4. Wang, Z., Wang, J., Shuai, S., and Ma, Q., "Effects of Spark Ignition and Stratified Charge on Gasoline $\mathrm{HCCl}$ Combustion With Direct Injection," SAE Technical Paper 2005-01-0137, 2005, doi:10.4271/2005-01-0137. 
5. Milovanovic, N., Blundell, D., Gedge, S., and Turner, J., "SI-HCClSI Mode Transition at Different Engine Operating Conditions," SAE Technical Paper 2005-01-0156, 2005, doi:10.4271/2005-01$\underline{0156}$.

6. Santoso, H., Matthews, J., and Cheng, W., "Managing SI/HCCl Dual-Mode Engine Operation," SAE Technical Paper 2005-010162, 2005, doi:10.4271/2005-01-0162.

7. Manofsky, L., Vavra, J., Assanis, D., and Babajimopoulos, A., "Bridging the Gap between $\mathrm{HCCl}$ and SI: Spark-Assisted Compression Ignition," SAE Technical Paper 2011-01-1179, 2011, doi:10.4271/2011-01-1179.

8. Chen, T., Xie, H., Li, L., Yu, W. et al., "Continuous Load Adjustment Strategy of a Gasoline HCCI-SI Engine Fully Controlled by Exhaust Gas," SAE Technical Paper 2011-01-1408, 2011, doi:10.4271/2011-01-1408.

9. Havstad, M., Aceves, S., McNenly, M., Piggott, W. et al., "Detailed Chemical Kinetic Modeling of Iso-octane SI-HCCI Transition," SAE Technical Paper 2010-01-1087, 2010, doi:10.4271/2010-011087.

10. Larimore J., Om E. H., Sterniak J., Jiang L., and Stefanopoulou A. G., "Experiments and Analysis of High Cyclic Variability at the Operational Limits of Spark-Assisted HCCl Combustion," American Control Conference (ACC), 2072-2077, 2012.

11. Sen A. K., Litak G., Edwards K. D., Finney C. E. A., Daw C. S., and Wagner R. M., "Characteristics of cyclic heat release variability in the transition from spark ignition to $\mathrm{HCCl}$ in a gasoline engine," Appl Energ, 88: 1649-1655, 2012.

12. Knop V., Michel J., and Colin O., "On the use of a tabulation approach to model auto-ignition during flame propagation in SI engines," Appl Energ, 88: 4968-4979, 2011.

13. Wang X., Xie H., Li L., Xie L., Chen T., and Zhao H., "Effect of the Thermal Stratification on SI-CAI Hybrid Combustion in a Gasoline Engine," Appl Therm Eng, 61: 451-460, 2013.

14. Persson, H., Sjöholm, J., Kristensson, E., Johansson, B. et al., "Study of Fuel Stratification on Spark Assisted Compression Ignition (SACl) Combustion with Ethanol Using High Speed Fuel PLIF," SAE Technical Paper 2008-01-2401, 2008, doi:10.4271/2008-01-2401.

15. Middleton R. J., Martz J. B., Lavoie G. A., Babajimopoulos A., and Assanis D. N., "A computational study and correlation of premixed isooctane air laminar reaction fronts diluted with EGR," Combust Flame 159: 3146-3157, 2012.

16. Benajes J., García A., Domenech V., and Durrett R., "An investigation of partially premixed compression ignition combustion using gasoline and spark assistance," Appl Therm Eng, 52: 468-477, 2013.

17. Williams B., Ewart P., Wang X., Stone R., Ma H., Walmsley H., Cracknell R., Stevens R., Richardson D., Fu H., and Wallace S., "Quantitative planar laser-induced fluorescence imaging of multi-component fuel/air mixing in a firing gasoline-direct-injection engine: Effects of residual exhaust gas on quantitative PLIF," Combust Flame, 157:1866-1878, 2010.

18. Yi, J., Wooldridge, S., Coulson, G., Hilditch, J. et al., "Development and Optimization of the Ford 3.5L V6 EcoBoost Combustion System," SAE Int. J. Engines 2(1):1388-1407, 2009, doi:10.4271/2009-01-1494.

19. Lippert, A., El Tahry, S., Huebler, M., Parrish, S. et al., "Development and Optimization of a Small-Displacement SparkIgnition Direct-Injection Engine - Stratified Operation," SAE Technical Paper 2004-01-0033, 2004, doi:10.4271/2004-01-0033.

20. Ikoma, T., Abe, S., Sonoda, Y., Suzuki, H. et al., "Development of V-6 3.5-liter Engine Adopting New Direct Injection System," SAE Technical Paper 2006-01-1259, 2006, doi:10.4271/2006-01-1259.

21. Xu, Z., Yi, J., Curtis, E., and Wooldridge, S., "Applications of CFD Modeling in GDI Engine Piston Optimization," SAE Int. J. Engines 2(1):1749-1763, 2009, doi:10.4271/2009-01-1936.

22. Joh, M., Huh, K., Noh, S., and Choi, K., "Numerical Prediction of Stratified Charge Distribution in a Gasoline Direct-Injection Engine - Parametric Studies," SAE Technical Paper 1999-01-0178, 1999, doi:10.4271/1999-01-0178.

23. Najt P. M., Kuo T. W., Cleary D. J., Eng J. A., and Brown B. L., "Auto-ignition Gasoline Engine Combustion Chamber and Method," US patent: US6971365, 2005.
24. Han, Z., Weaver, C., Wooldridge, S., Alger, T. et al., "Development of a New Light Stratified-Charge DISI Combustion System for a Family of Engines With Upfront CFD Coupling With Thermal and Optical Engine Experiments," SAE Technical Paper 2004-01$\underline{0545}, 2004$, doi:10.4271/2004-01-0545.

25. Iyer, C., Han, Z., and Yi, J., "CFD Modeling of a Vortex Induced Stratification Combustion (VISC) System," SAE Technical Paper 2004-01-0550, 2004, doi:10.4271/2004-01-0550.

26. Xu, Z., Yi, J., Wooldridge, S., Reiche, D. et al., "Modeling the Cold Start of the Ford 3.5L V6 EcoBoost Engine," SAE Int. J. Engines 2(1):1367-1387, 2009, doi:10.4271/2009-01-1493.

27. Stach, T., Schlerfer, J., and Vorbach, M., "New Generation Multihole Fuel Injector for Direct-Injection SI Engines - Optimization of Spray Characteristics by Means of Adapted Injector Layout and Multiple Injection," SAE Technical Paper 2007-01-1404, 2007, doi:10.4271/2007-01-1404.

28. Kawamoto, M., Honda, T., Katashiba, H., Sumida, M. et al., "A Study of Center and Side Injection in Spray Guided DISI Concept," SAE Technical Paper 2005-01-0106, 2005, doi:10.4271/2005-01-0106.

29. Gosman, A.D., and Marooney, C.J. "Development and validation of a computer code for Diesel combustion", IDEA Project, Subprogram E1, October, 1991.

30. Reitz, R. and Diwakar, R., "Effect of Drop Breakup on Fuel Sprays," SAE Technical Paper $\underline{80469}, 1986$, doi: $10.4271 / 860469$.

31. Cd-adapco, "Methodology, STAR-CD VERSION 4.14," 2010.

32. Jones W. P., "Prediction methods for turbulent flames," in Prediction Methods for Turbulent Flow, Kollmann W., ed. (Hemisphere, Washington, D.C., 1980), pp. 1-45.

33. Angelberger, C., Poinsot, T., and Delhay, B., "Improving NearWall Combustion and Wall Heat Transfer Modeling in SI Engine Computations," SAE Technical Paper 972881, 1997, doi:10.4271/972881.

34. Bangquan H., and Chengjun D., "Characteristics of Various Alcohol-Gasoline Blends," Journal of Combustion Science and Technology, 18(4): 301-308, 2012.

35. Li, N., Xie, H., Shen, M., and Zhao, H., "CFD Study on Effects of Thermal and Residual Gas Inhomogeneous Distribution on Autoignition of Gasoline HCCl Combustion," SAE Technical Paper 2010-01-0160, 2010, doi:10.4271/2010-01-0160.

36. Krishna B. M., and Mallikarjuna J. M., "Comparative study of in-cylinder tumble flows in an internal combustion engine using different piston shapes-an insight using particle image velocimetry," Exp Fluids 48: 863-874, 2010.

\section{CONTACT INFORMATION}

Prof, Hui Xie

State key laboratory of Engines

Tianjin University

Tianjin, China

Weijin Road 92, Nankai Distinct

xiehui@tju.edu.cn

\section{ACKNOWLEDGMENTS}

The study is a part of the National Science Fund project (Grant 51206118) supported by the National Science Fund Committee of China, and State Key Project of Fundamental Research Plan (Grant 2013CB228403) supported by the Ministry of Science and Technology of China. The authors would also like to acknowledge the China Scholarship Council (CSC), which funded the first author for one year study at Brunel University. 


\section{DEFINITIONS/ABBREVIATIONS}

SI - spark ignition

CAl - controlled auto-ignition

SACI - spark-assisted compression ignition

PFI - port fuel injection

GDI - gasoline direct injection

3-D - three-dimensional

CFD - computational fluid dynamics

IMEP - indicated mean effective pressure

CCV - cycle-to-cycle variation

PLIF - planar laser-induced fluorescence

MFB - mass fraction burned

RANS - Reynolds-averaged Navier Stokes

PISO - pressure-implicit with splitting of operators

4VVAS - 4-variable valve actuation system

EVO - exhaust valve open
EVC - exhaust valve close

EL - exhaust valve lift

IVO - intake valve open

IVC - intake valve close

IL - intake valve lift

EGR - exhaust gas recirculation

NVO - negative valve overlapping

RGF - residual gas fraction

TDC - top dead centre

SOI - start of injection

SR - swirl ratio

TR - tumble ratio

CTR - cross tumble ratio

Vm - velocity magnitudes

TKE - turbulence kinetic energy

All rights reserved. No part of this publication may be reproduced, stored in a retrieval system, or transmitted, in any form or by any means, electronic, mechanical, photocopying, recording, or otherwise, without the prior written permission of SAE International.

Positions and opinions advanced in this paper are those of the author(s) and not necessarily those of SAE International. The author is solely responsible for the content of the paper. 